TITLE: FMIT DIRECT-CURRENT BEAM MONITOR

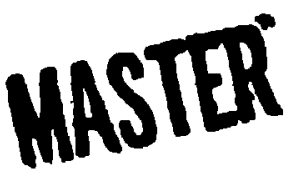

AUTHOR(S): A. T. Brousseau and D. D. Chamberlin

SUBMITTED TO: 1981 Particle Accelerator Conference March 11-13, 1981, Washington DC
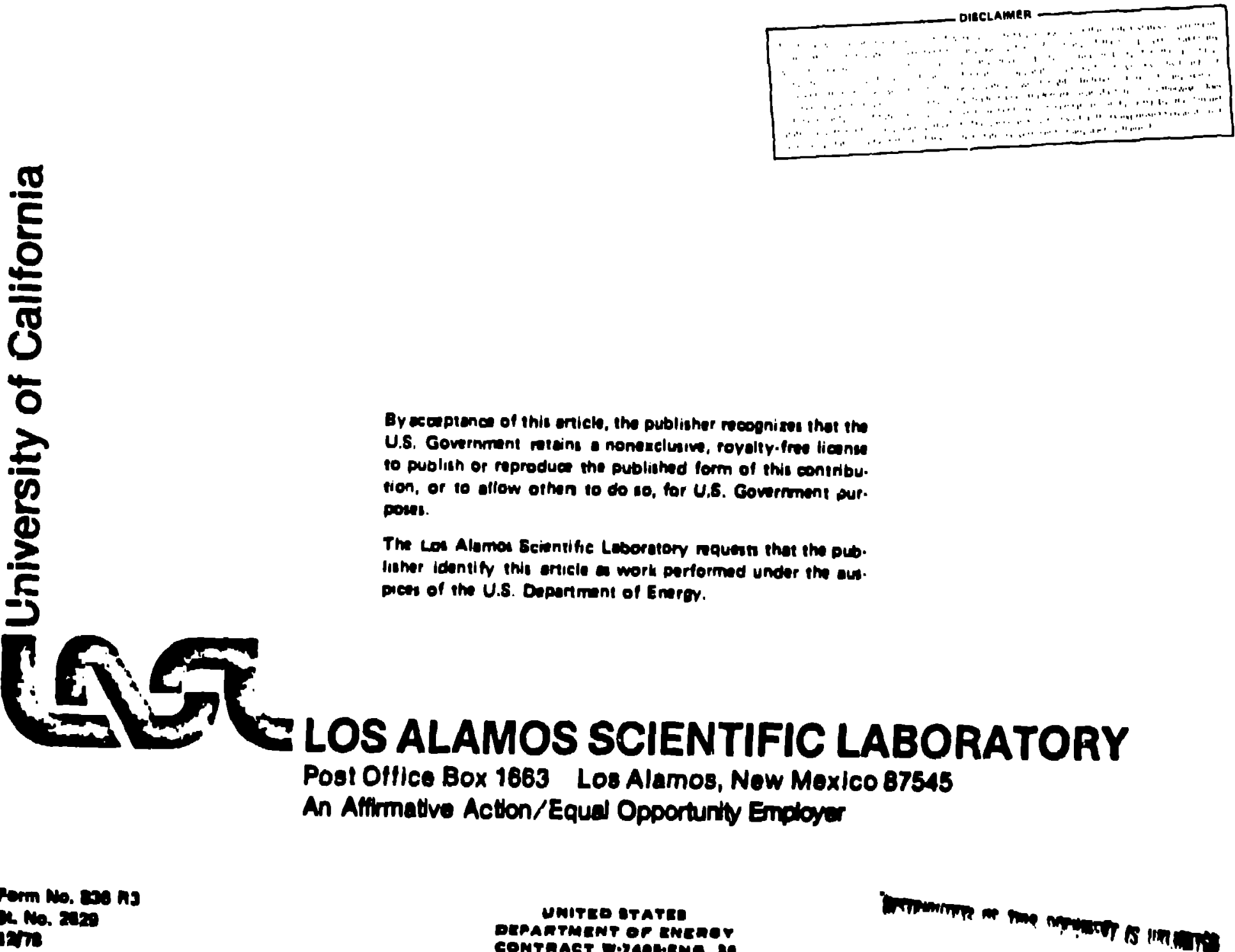

By ecaptende of this errich, the publishy, reognises that ine U.S. Government mesine a nonerelusien, rovalty. fres lieanne 10 publish or reproduce the publistind form of this conitibu. rion, or 10 aflow othen to do 10 , tor U.S. Government sur. pois.

The Led Alames Beientife Lesoratery nquest that the pub. lisher idantipy this enicle a work pertormed under ins as. pices of ith U.S. Dapartment of Enerer.

umire orateo Derantment of rucher

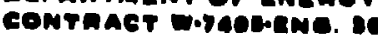

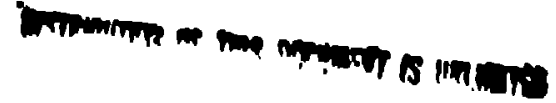

$\gamma^{p}$ 


\section{FMIT DIRECT-CURRENT BEAM MONITOR *}

A. T. Brousseau and D. D. Chamberl in ${ }^{\star *}$

Los Alamos National Laboratory, Los Alamos, New Mexico 87545

\section{Introduction}

The prototype injector section for the Fusion Materials Irradiation Test (FMIT) Facility being developed at the Los Alamos National Laboratory requires that beam parameters be non interceptively monitored. This report describes the application of a single. toroidal core, coupled with verv simple circuitry, that results in the production of a simple instrument, and eliminates the problems inherent in the $F$ araday cup technique for the current measurements of the FMIT injector beam.

A single toroidal core, fitted about the infector beamline, will noninterceptively couple to the beam current by magnetic induction, allowing a quant itative measurement of that current over a range of 0.5 to $100 \mathrm{~mA}$, with an expected $0.05 \%$ linearity. The sensor electrunics are based on the second harmonic modulation technique, and have benefited from simflar devices reported from CERN ${ }^{1}$ and $L L L^{2}$. The prototype design allows the user a choice of current-readout modes (that is, analog or digital), as well as a fiber-optic link arive for remoce computer acquisition.

\section{Theory of Operation}

To acquire a linear, secondary, output-sense current from the toroidal winding $L-1$ ( $F / g$. la) as a function of the applied input primary current (injector beaml. It is essential to operate within the core's linear saturation region. This linear saturation region is illustrated on the B-H pmofile as point " $A$ " for beginning-core saturation, and point " $B$ " for upper level saturation $(\mathrm{F} / \mathrm{g} . \mathrm{iC}$ ). In our experimental monitor, we are using a $0.1-\mathrm{mm}$-thick, tape-wound core of Permalloy square 80 material.

A bipolar, stabilized, square-wave current raveform, operating at $-600 \mathrm{CS}$, is applied to the principal torold winding $L-l$ (F $\mathrm{g}$. $\mathrm{la}$ ). This modulating waveform ( $F \mid g .10)$ drives the core (at the flattopped peaks) to the first saturation-level point " $A$ " $(F: g . i c)$. If the driving amplitude (for given core mater(a) should be insufficient to reach the initial saturation level "A", a second winding (bias) $L-2$ is wound over $L-l$ and is supplied with an appropriate constant current sufficient to reach this saturation

Whork performed under the auspices of the US Department of Energy.

* West inghouse-Hanford enp loyee work ins at Los Alamos. level. In practice, we have found that just a fow milliamperes is adequate to reach this level. From this point on, further current applied to the primary (injector beam) will continue to saturate the core Iinearly towards the upper-level saturation point "B". This linear saturation region, points "A" to " $B$ " (lineer saturation $r$ ise) corresponds to a linear decrease in the inductance of $L-1$. A small rectifying component of the modulating frequency is fed back on winding $L-4$ to allow a stabilizing feedback to the linear operational point, " $C$ ".

\section{Circuit Function}

The electrical block diagram for the current monttor is shown in Fig. 2. The ac signal developed by the toroid $L-1$ is applied to the input of a precision, full-wave rectifying circuit through a narrow-band $(10 \mathrm{c} / \mathrm{s})$ fliter to the inverting input of the chopperstabilized operational amplifier. To eliminate the possible hetrodyning conflict that might exist between the amplifier's chopping frequency and the $600-\mathrm{c} / \mathrm{s}$ ripple of the system driving frequency, we interposed the filter as a precautioniry measure. In retrospect, a simple RC network may be just as effective.

In view of the low-level dc offset voltages that must be amplified, very de iberate care must be exercised in the selection of ligh-quality, low-drift, operational ampliffers, passi:e components, and attention to circuit-board layouts, ali in an effort to minimize the orift problems inherent with direct coupled systems. Conditioning the $n^{4} r$ within the compartment housing the circuit boards will measureably improve the overali stability of the circuits discussed. Several high-quality operat lonal amplifiers were evaluated for this application, and most were found to be sat isfactory. In the final ana'ysis, and with the intentions of further improving on the long-term stability of the monitor, we decided in favor of the chopper-stablilized amplif ters.

\section{Ioroid Driver}

A modified Wien bridge osclllator, operating at a trabillized frequency of $700 \mathrm{c} / \mathrm{s}$, generates a $28-\mathrm{V}$ peak-to-peak, square wave (50x duty cycle) with an excellent flat-topped characteristic of less than ix droop. The output of the square wave generator is applied to a pair of emitter followers which in turn provide a constant current drive to the torotdal core $[-1$. The emitter follower orivers are optimally biased

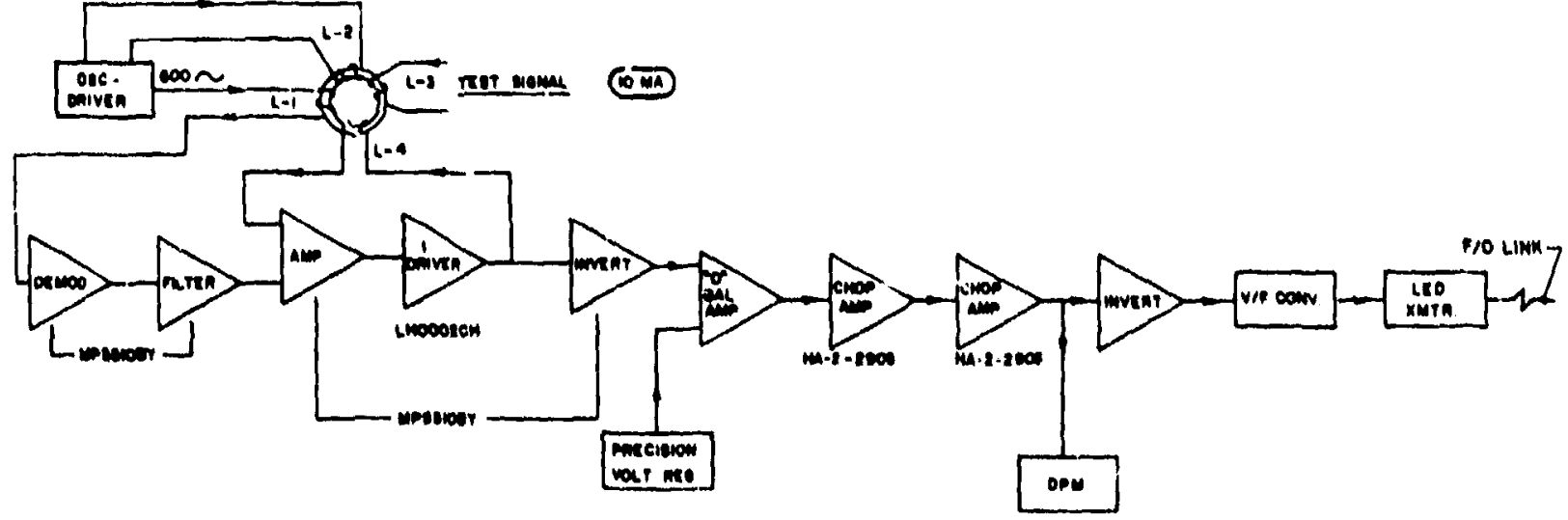

Fig. 1. Schematic for transductor operation. 
T-1-PAAT No. $222-A-81=04$

TERMALL OY GUARE $D$ MATL.

O.D. $-62 \mathrm{~mm}$
I. D. $-127 \mathrm{~mm}$

W10TH $-12.7 \mathrm{~mm}$

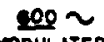

PDULATED

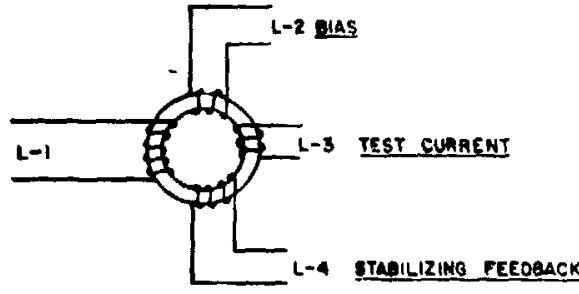

(A)

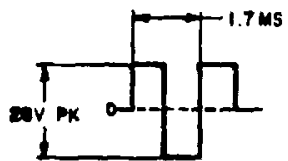

(B)

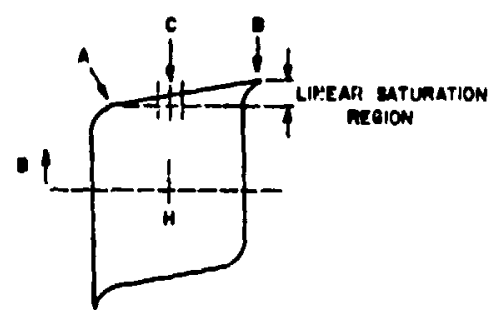

(c)

Fig. 2. Elsctronics block diagram.

for minimum crossover distortion. Tue driver's outputamplitude stablitty is maintained by high-level feedback to the amplifier of the oscillator driver.

\section{Toroidal Core}

The toroldal core used in the prototype monitor measures $127-\mathrm{mm}$ ID $\times 1 £ 2-\mathrm{mm} 00$ and is $12.7 \mathrm{~nm}$ wide. The core-grade, Permalloy square 80 is tape-wound with $0.1-m m$-thick laminate and is aluminum encasel. The major winding $(L-1)$ consists of approximately 308 turns of 26 Permalese-coated magnetic wire, wound over $95 \%$ of the core's toroidal length, with a separation between turns of roughly one wire diameter. The bias winding $(L-2)$ and the test-signal winding $(L-3)$, each six turns, are wound over the full length of the major winding. Each winding is terminated into $46-\mathrm{cm}-1$ long. color-coded, figtailed leads. To stabilize the windings, the core is immersed in Dow Sylgard 182. This immersion process is performed several times, the core being allowed to dry between immersions. This process is performed as many times as necessary, until a coating $0.1-0.25 \mathrm{~mm}$ thick is achieved. The encapsulated core is then fitted with an outer electromagnetic shieid.

\section{Instrument Descriotion}

The initial packaging style of the monitor was influenced by factors such as circuit function isolation, ease of fabrication, field maintenance, and system cooling. The functional electronic circuits are divided into three separate printed circult boards. These three system boards and two plug-in type, power-supply modules are mounted on a hinged subchassis and installed at the center (inner) location of the main case. A $6.35-\mathrm{cm}$ cooling fan is attached at one end of the case, to allow uniform airflow over both sides of the circuit boards. The front panel is horizontally hinged to allow easy access to the circuit boards. The $c$ ase is made of lightwelght aluminum measuring $15.24 \mathrm{~cm} \times 20.3 \mathrm{~cm} \times 38 \mathrm{~cm}$. and will be wall-mounted adjacent to the beamline.

\section{References}

?. K. Unser, ISR Diviston, CERN, private communicaticn, 1980.

2. R. Rathjen, Lawrence Livermore Lab., private commun ication, 1980. 